\title{
The Country-Level Income Structure of the WORLD-ECONOMY
}

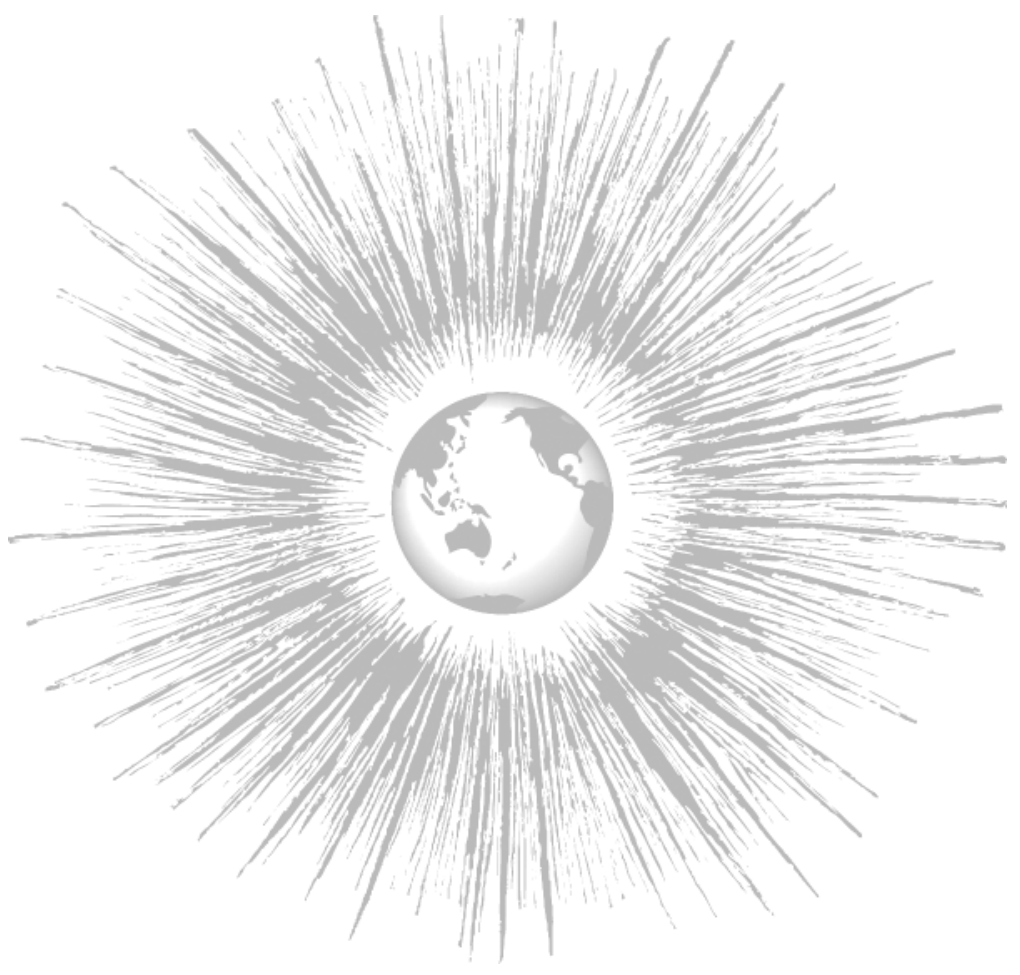

ABSTRACT:

World-systems sociologists have long recognized a three-tier structure in the world economy, which comprises peripheral, semiperipheral, and core groups of countries. Thi paper introduces a new database tool for ana lyzing this structure of the world-economy in terms of national income, the Structure of the World-Economy (SWE) analytical tool. It can be used to chart the structure of the world-economy in terms of income per capit for any year from 1960-2000 based on param eters selected by the user. Results confirm the existence of a three-tier structure of the world-economy that is relatively stable over the period for which data are available. A con tinuous set of benchmarks for the boundary points separating zones of the world-economy are reported for the period $1975-2002$, along with a brief analysis of national mobility across those boundaries. Only seventeen countries (out of IO3) made lasting transitions between zones of the world-economy over the study period, mostly due to changes in the prices of natural resources. The results of this study suggest that development policy formation should focus more on the attainable goal of transitioning countries from the periphery to the semiperiphery of the world-economy, and less on achieving an absolute standard of "developed" or core country status.

Salvatore J. Babones

\section{INT RODUCTION}

A key contribution of Wallerstein's (1974) Modern World-System, Volume I

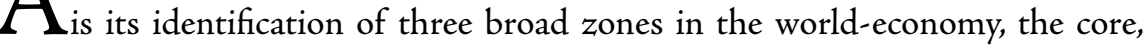
the semiperiphery, and the periphery. Embracing this structured view of the world-economy, several groups of scholars have attempted to properly allocate the countries of the world among the three Wallersteinian zones. These attempts have in general been successful, with three-zone structures emerging from network analyses of patterns of trade, network analyses of economic, political, and military relationships, and distributional analyses of income levels. All of these analyses, using very different methods and data, yield roughly similar groups of countries for each of the three structural zones. This tends to confirm the basic validity of the model of a world-economy divided into three structural zones

Given that the existence of a three-zone structure to the world-economy has been several times confirmed by a wide variety of studies, it is indeed ironic that we do not possess a widely-accepted, up-to-date set of benchmarks for position in the world-economy. Since Wallerstein's approach to world-system structure is relational, based on the system-wide division of labor, a relational approach to establishing the divisions separating core, semiperiphery, and periphery would be most theoretically appropriate. This is, however, difficult to implement in practice. Several attempts (reviewed below) have been made to distinguish roles in the global division of labor using network analyses of international trade flows. Such

Salvatore J. Babones

Department of Sociology

University of Pittsburgh

Pittsburgh, PA 15260

sabones@pitt.edu

http://www.pitt.edu/ ssbabones/

JOURNAL OF WORLD-SYSTEMS RESEARCH, XI, I, JULY 2005, 29-55 bttp://jwsr.ucr.edu/

ISSN $1076-156 \mathrm{X}$

(C) 2005 Salvatore J. Babones 
network-based methods are highly data-intensive, and thus difficult to update regularly. Moreover, network-based methods cannot be applied out-of-sample: there is no way to determine the world-system zone of any country that is not in the benchmarking sample of countries whose trade flows are analyzed. Because of these limitations, network analyses of world-system structure have been conducted at discrete time points, and have not formed the basis for continuous time series of boundary points between zones of the world-economy.

Income-based methods are more promising for this purpose. They are not very data-intensive; they require little specialist knowledge; they can be applied to most of the countries of the world for which statistics of any kind are reported. Benchmark boundary points in the global income distribution can be applied out-of-sample with little loss of validity, especially if the income level of the country in question is not very near a boundary point. Income-based methods carry the additional advantage that they can be updated annually, usually about I8 months after the end of the study period.

However, the two existing income-based trichotomizations of the worldeconomy (Arrighi and Drangel 1986; Korzeniewicz and Martin 1994) suffer from some drawbacks as benchmarking studies. They use cumbersome methodologies that require a great deal of human judgment in setting zonal boundaries (i.e., they have not developed robust statistical definitions of what constitutes a boundary point). Also, they both use all available countries for each time period that they study, reducing the inter-temporal comparability of their zonal boundaries. The do not report annual results and, of course, they are both now rather out-of-date. Major improvements in the income-based approach are possible, which would give the resulting benchmarks much wider and simpler application. To be fair, computational methods are widely available today that were not conveniently available to either Arrighi and Drangel or even Korzeniewicz and Martin.

In this paper I begin by exploring the development of the concept of a threetier structure of the world-economy. Second, I review the empirical literature on efforts to divide the world economy into peripheral, semiperipheral, and core zones. Third, I present an update of the Arrighi-Drangel (1986) methodology for uncovering the structure of the world-economy, introducing a public-use spreadsheet, the Structure of the World-Economy (SWE) analytical tool, that can be used by other researchers for determining their own benchmarks using data operationalizations of their choice. Fourth, I report new historical income-based benchmarks for the zones of the world-economy based on results from the SWE tool. I conclude with directions for future development of the SWE tool.

\section{THE THREE-TIER WORLD-ECONOMY}

At least since Wallerstein's (1974) seminal work on the origins of the modern world-system, mainstream sociologists have recognized the long-standing existence of a relatively stable structure to the international system of states. Wallerstein defined a world-system as

a social system, one that has boundaries, structures, member groups, rules of legitimation, and coherence... life within it is largely self-contained, and...the

dynamics of its development are largely internal. (p. 347)

According to Wallerstein, there have historically existed two types of worldsystems: world-empires and world-economies. World-empires are characterized by the organization of an entire world-system under a single state structure, while world-economies are characterized by the existence of competing states within the system. Today's modern world-system is postulated to be a world-economy, comprising all of the countries and areas in the world today.

\section{Structure of the Post-WWII World-Economy}

In Wallerstein's (1974) model, all world-systems are structured around a system-wide division of labor:

This division is not merely functional — that is, occupational—but geographical...it is a function of the social organization of work, one which magnifies and legitimizes the ability of some groups within the system to exploit the labor or others, that is, to receive a larger share of the surplus. (p. 349)

The modern world-economy is no exception. Wallerstein (1974: 347-357, 1979: 66-73) and theorists following in the Wallersteinian tradition (e.g., ChaseDunn 1998: 20I-214; Arrighi and Drangel I986: 9-30) have recognized a strong international component to the functional division of labor in the modern worldeconomy. They claim that countries at the "core" of the world-economy tend to specialize in "core production":

the production of core commodities using relatively...capital intensive technology and relatively skilled and highly paid labor (Chase-Dunn 1998: 346 ),

while countries in the "periphery" of the world economy tend to specialize in "peripheral production":

the production of peripheral commodities using technology which is relatively low in capital intensity and labor which is paid low wages and is usually politically coerced compared to labor in core areas. (Chase-Dunn 1998: 347) 
Economic activity in the modern world-economy, however, is not structured neatly within national borders. The very essence of the world-economy as such is that commodity chains cut across national borders, tying the entire interstate system into a single world-system. Thus, in the Wallersteinian tradition, coreperiphery hierarchies are embedded in commodity production chains as much as in state-to-state relations. In this view,

Core activities are those that command a large share of total surplus produced within a commodity chain and peripheral activities are those that command little or no such surplus. All states enclose within their boundaries both core and peripheral activities. Some (core states) enclose predominantly core activities and some (peripheral states) enclose predominantly peripheral activities. As a consequence, the former tend to be the locus of world accumulation and the latter the locus of exploitation and powerlessness (Arrighi and Drangel 1986: 12-13).

Arrighi and Drangel (1986) further argue that the self-reinforcing advantages that come from having a high concentration of core activities within a state (and the complementary self-reinforcing disadvantages that come from a concentration of peripheral activities) tends to polarize the world-economy into core and peripheral states (p. 26). However, in between the core and the periphery there exists a group of states which contain an "even mix" (Arrighi and Drangel 1986: 26) or "balance" (Chase-Dunn 1998: 210) of core and peripheral type production. These are the states that Wallerstein (1974) termed semiperipheral (p. 349). In the Wallersteinian tradition these states are postulated to represent a kind of "safety valve" that is necessary for the perpetuation of core-country capitalism (Wallerstein 1979: 70). As formerly leading industrial sectors mature, declining profit margins push production out of core countries in search of lower-cost environments. The countries of the semiperiphery use their cost advantages vis-à-vis the core to attract these declining industries, at the same time extending core capitalists ability to maintain the profitability of a given production process. The relationship is thus symbiotic, and self-propagating (Arrighi and Drangel 1986: 26-27). In some sense, the states of the semiperiphery can be thought of as a sort of second-run theater for what were formerly core activities.

\section{Location of the Semiperiphery}

On the location of the semiperiphery, Arrighi and Drangel (1986) take Wallerstein to task for inconsistent, vague, and even contradictory depictions (PP. 13-I4). Arrighi and Drangel themselves, in a section titled "The Concept of Semiperiphery," offer a highly theorized account of how core-periphery hierarchies are created and perpetuated (PP. 16-26), complemented by a short and tentative description of how semiperipheries might come to exist (PP. 26-28). Chase-Dunn (1998) lauds the concept of the semiperiphery as "one of the most fruitful concepts introduced by Immanuel Wallerstein" (p. 210) only to cast out entirely the idea that there are discrete zones in the world economy in favor of arguing for a hierarchical continuum of power among countries (PP. 2IO-214). He concludes that "the vocabulary of zones is simply a useful metaphor" (p. 214). Terlouw (1993) goes even further to conclude that the semiperiphery is "a blurred zone on the continuum between core and periphery" (p. 87).

On the other hand, anecdotal evidence suggests that a qualitatively intermediate zone exists somewhere between the core and what are conventionally considered peripheral countries. Wallerstein's own list of semiperipheral countries is a case in point. According to Wallerstein, as of 1979:

It includes the economically stronger countries of Latin America: Brazil, Mexico, Argentina, Venezuela, possibly Chile and Cuba. It includes the whole outer rim of Europe: the southern tier of Portugal, Spain, Italy, and Greece; most of Eastern Europe; parts of the northern tier such as Norway and Finland. It includes a series of Arab states: Algeria, Egypt, Saudi Arabia; and also Israel. It includes in Africa at least Nigeria and Zaire, and in Asia, Turkey, Iran, India, Indonesia, China, Korea, and Vietnam. And it includes the old white Commonwealth: Canada, Australia, South Africa, possibly New Zealand. (Wallerstein 1979: 100)

Arrighi and Drangel (1986) make clear that they do not see much science in Wallerstein's diverse list of countries, accounting, as they point out, for well over half of the world's population ( $p+13)$. They suggest that:

As a matter of fact, the list simply includes all states that seem to occupy an intermediate position in the world-economy from the point of view of either their income levels or their power in the interstate system. The connection between such positions and the structure of the world-economy, as spelled out in the concept of semiperiphery, is completely lost, and the list could have been drawn up without any reference to such a concept. (Arrighi and Drangel I986: I4)

Arrighi and Drangel met this need for a formalization of the concept of the semiperiphery by positing that each national economy is composed of a mix of core-type and peripheral-type activity. Countries hypothetically can be ranked on the basis of the percentage of core-type activity in their economies. Below a certain percentage, the PC (perimeter of the core) boundary, countries have little or no power to upgrade their mix of activities; below an even lower percentage, the PP (perimeter of the periphery) boundary, countries have little or no power even to prevent the downgrading of their mix of activities. In this conceptualiza- 
tion, the two boundaries delineate the three zones of the world-economy. The semiperiphery is composed of those countries with per capita national income levels that lie between the PC and PP boundaries.

It should be noted that this economistic approach is not shared by all worldsystems analysts. In particular, Chase-Dunn and Hall (1997) elaborate a typology of semiperipheral development that is based more broadly on power and capacity to effect change than on simple income or wealth measures. Analyzing world-systems more broadly (i.e., not limiting themselves to the post-1950 worldeconomy), they identify cases in which semiperipheral states successfully challenged existing world-system hierarchies through both military and commercial channels. Applied to the period of this study, their thinking might suggest, for example, that the Soviet Union be seen as a semiperipheral challenger to US post-war hegemony. This suggests a level of agency among semiperipheral actors that is absent from the Arrighi-Drangel conceptualization. For the purposes of this study, it is sufficient to note that the semiperiphery is in an economically subordinate position to the core of the world-economy, even though it may challenge the core in other ways (militarily, scientifically, ideologically, etc.). The merchant city-states that Chase-Dunn and Hall identify as semiperipheral in their power-based typology would, in the context of this paper, be classified as part of the core of the world-economy on account of their high income levels.

\section{THREE APPROACHES TO STRUCTURE}

Several attempts have been made over the past twenty years to operationalize empirically the concept of world-system position. In one group of studies, methods developed for social network analysis have been applied to world trade and other international data to delineate structurally equivalent blocks of countries (Snyder and Kick 1979; Nemeth and Smith 1985; Kick 1987; Smith and White 1992; Van Rossem 1996). In a second group of studies, countries have been clustered by income level (Arrighi and Drangel 1986; Korzeniewicz and Martin 1994). Studies in both traditions consistently uncover a three-zone partition of the world-economy. A third group of studies, however, is premised on the idea that the countries of the world fall on a continuum from core to periphery, with no attempt made at partitioning into zones (Terlouw 1992; Van Rossem 1996; Kentor 2000).

Chase-Dunn (1998) argues strongly for this third approach that operationalizes world-system structure as multi-dimensional convergence of hierarchies of "political, military, and economic types of power/dependence relations" (p. 215). In this approach, world-system position is not a discrete role variable, but is more of a continuous status variable. Higher-status countries do not directly exploit specific lower-status countries, but are simply more able to gain advantages in the global economy than are their competitors.

This critique, however, does not invalidate the idea of a discrete partitioning of the world-economy, but complements it. The division of the world-economy into discrete zones, however, is probably best thought of in terms of roles played by states, contra groups of specific other states. Status in the world-system, however, is more of an absolute measure of a state's ability to project its will in the global arena. Thus, while India and China are clearly not core countries on the basis of their roles in the world-economy, they are high-status countries due to their large populations, activist international policies, and nuclear capabilities. On the other hand, while the Netherlands and Switzerland play unambiguously core country roles in the world-economy (both being wealthy centers of trade and administration), they carry less weight in the international arena than, say, China. The two perspectives are not mutually exclusive.

The arguments presented in this article are concerned more with differences between zones of the world-economy in the relationships among economic variables than with relative state status or power. Consequently, I will use a zonal characterization of the world-economy, rather than a continuous one. For a variety of reasons, however, network studies of world-system structure have yet to yield a convincing partition of the world-economy, while data limitations remove many countries from the network analyses, especially for periods before 1980 . Thus, I turn to a third tradition of world-system classification for my methodological inspiration. This tradition, represented by two benchmarking studies employing near-identical methodologies, maintains that world-system zones can be differentiated on the basis of income alone (Arrighi and Drangel I986; Korzeniewicz and Martin 1994).

In what follows, I discuss in more detail the literature in the network and continuum traditions. I then move on to review the income tradition. My own operationalization of the structure of the world-economy, developed in the context of the income tradition, will be presented in the following section.

\section{The Network Tradition}

In some ways, the network analysis tradition comes the closest to capturing the idea of world-system zones as roles in the world-economy. Early studies, such as Snyder and Kick (1979) and Nemeth and Smith (1985) have been largely superceded by similar work by the same authors. Of the later studies, Kick (1987) and Van Rossem (1996) both build their blockmodels on multiple networks of dominance in world trade, military power, and political memberships. Although they use similar variable lists, they use very different methodologies, and so arrive at very different results. 
Kick (1987) builds his network model on eight overlapping networks of relationships among countries: trade, aid treaties, transportation/communication treaties, sociocultural treaties, administrative/diplomatic treaties, armaments transfers, and miliary conflict. For each network, Kick codes the ties between each pair of countries into a o/I dichotomy. His data represent 130 countries for roughly the period I970-75. Kick finds II structural blocks. His first block is an obvious world-systems "core," but his other blocks represent various other groupings of countries. Kick's analysis is highly idiosyncratic, suffers from necessary but arbitrary dichotomization, and does not yield obvious world-systems categories. While it is interesting to compare Kick's results to those of other studies, Kick's methodology does not provide a model for basic world-systems benchmarking.

Smith and White (1992) build their model around the concept of the "regular" or role equivalence of patterns of world trade. Role equivalence is an elaboration of the more familiar structural equivalence concept in network analysis. Structural equivalence categorizes subjects on the basis of the similarity of their relationships with specific blocks of other subjects. Role equivalence goes one step further to group together blocks of subjects that have similar sets of structural relationships. Thus, if former French colonies form a structural block in relation to France and former British colonies another structural block in relation to Britain, under regular equivalence former colonies of all countries would form a role block in relation to all former colonists.

As a result of their use of role equivalence, Smith and White (1992) find fewer blocks than other network studies of world-system structure. In fact, they confirm the three-tier structure common to most theoretical models, although they detect some splitting of blocks two and three into sub-blocks. They find one block (core) with an overwhelming volume of in-block trade, a second block that trades heavily with the core but not within itself, and a third block with very little trade of any kind (p. 882, Table 6).

There are three major drawbacks to the Smith and White methodology. One is the limited number of countries for which data are available. Their study was limited to just 63 nations, and new data for most of the remaining countries of the world are not forthcoming. Second, their results may be clouded by currency issues. The United Nations commodity trade statistics used by Smith and White are denominated in dollars at official exchange rates, and thus grossly misrepresent the true volumes of trade for all countries before the early i97os and for most countries even today. Third, network analysis has not progressed to the point where weighted analyses are possible. Smith and White mitigate this problem by excluding countries with fewer than I million population, but all remaining countries are weighted equally in the analysis.
Van Rossem's (1996) methodology is similar to Kick's. It involves the network analysis of dichotomized measures of import dependence, export dependence, diplomatic ties, arms trade, and troop presences. Van Rossem, however, uses role equivalence as his primary measure, rather than structural equivalence. However, his classification of world-system "roles" lacks face validity when he places China, Brazil, and Saudi Arabia in the 1993 core while Sweden and Switzerland are placed in the semiperiphery and Norway, Ireland, and Israel are relegated to the periphery. These odd results are probably an artefact of how he chose to operationalize his variables: he measures "export dependence," for example, as having exports greater than I\% of GDP. Such high levels of dependence do not, of course, represent "dependence" at all, but are more likely a sign of economic strength. His measures of international prominence are more meaningful, however, and will be discussed in the section on world-system continua below.

All network-based methodologies suffer in varying degrees from the same shortcomings as Smith and White (1992). It is also difficult to envisage how network-based benchmarks can be applied out-of-sample: in other words, where does one classify countries that are not in the study? With data available for only 6o-80 countries, some two-thirds of the countries of the world remain unclassified by network methods (though admittedly these are mainly smaller countries). Until these major methodological problems are solved, studies in the network tradition will be more useful for analyzing world-system structure in detail at one point in time than for establishing continuous time series of worldsystem zone boundaries.

\section{The Continuum Tradition}

The continuum tradition, built on the theoretical work of Chase-Dunn (1998), emphasizes the comparative ranking of states on a continuum or multiple continua of status and power. Three major studies to date have operationalized such continuous status hierarchies: Terlouw 1992, Kentor 2000, and Van Rossem 1996. I discuss each of them in turn.

Terlouw (1992) uses the mean level of six indicators to operationalize what he calls "mean coreness." These are level of trade, stability of trade, GDP per capita, military power, embassies sent and received, and diplomats sent and received. Terlouw's coreness measure is a good first approximation of world-system status, but it suffers from three key drawbacks: the even weighting of each of these factors in the final measure, the big country bias, and the lack of geographic controls.

On the first issue, it is difficult to equate the combined importance of embassies and diplomats, on the one hand, with GDP and military power on the other. 
Second, his measures seem to be highly correlated with country size. This is not a problem for a measure of status, or "punch." It is a problem for the study of role position-which is not, to be fair, what Terlouw sets out to study. Third, Terlouw makes no accommodation for geography, and it would be difficult to see how he could. Countries with hostile neighbors, for example, will have larger militaries, but will in fact be less secure, not more secure, than isolated countries with small militaries. In any case, Terlouw's work has been largely superceded by work in the same tradition by Kentor (2000).

Kentor takes a much longer view than any of the other studies considered here, attempting to measure world-system status over the entire 2oth century. He starts with measures of countries' positions on each of ten status variables, grouped into three dimensions: economic power, military power, and global dependence. He was not able to assemble data for all variables for all countries at all time periods, but used mean $z$-scores within each dimension to cover for missing data as long as one measure existed for each dimension. He weights economic and military power equally, but gives dependence only half weight, on the basis of the low face validity of his results when dependence was weighted fully.

Kentor's measures of world-system status are reported for 1900, 1930, 1950, I970, and 1990. Although he musters an impressive 98 cases for 1998, he has only 52 countries in his database for 1970-and this despite a relatively liberal attitude towards missing data. Kentor's is probably the most careful study to date in the tradition of measuring world-system status on a continuum of relative power, but the unlikelihood of ever assembling the data for status in 1970 or earlier makes it difficult to use as a standard for studying long-term shifts in status. Kentor's method will probably prove most useful for studying changing relative strengths within the core.

An interesting and generally overlooked operationalization of world-system status is provided by Van Rossem's (1996) ranking of network prominence for 163 countries and territories in 1993. Van Rossem's prominence rankings suffer from the same variable measurement drawbacks as his network study (prominence is a measure of network centrality arising from his network analyses), but the idea is intriguing. A better-designed study using network prominence as a measure of status would nicely tie together the network and continuum traditions operationalizing hierarchy in the world-economy.

\section{The Income Tradition}

World-systems sociologists generally agree that all states contain some mix of core and peripheral type activities within their borders. If it is the case that core type activities are vastly more remunerative than peripheral type activities, it should be possible to use national GNP per capita as a proxy for the level of core activity in the productive mix of an economy. As Arrighi and Drangel argue in their landmark 1986 article:

The greater the weight of peripheral activities in the mix falling within the jurisdiction of a given state, the smaller the share of the total benefits of the world division of labor commanded by the residents of that state. The differences in the command over total benefits of the world division of labor must necessarily be reflected in commensurate differences in the GNP per capital of the states in question. We can therefore take GNP per capita expressed in a common monetary unit as an indirect and approximate measurement of the mix of core-peripheral activities that fall within the jurisdiction of a given state. (p. 3I)

In their income-based approach to delineating the zones of the world-economy, Arrighi and Drangel (I986) plot histograms of the sum of the populations of nations falling into national income bins of .I points on a logarithmic scale (base IO). Thus, for example, all nations with logged income between 2.0 and 2.I ( $\$ 100$ and $\$ 125.89$ ) have their populations assigned to the 2.0/2.I bin; all nations with logged income between 2.I and 2.2 (\$125.89 and \$158.49) have their populations assigned to the 2.I/2.2 bin; etc. Due to the fine level of the bins and the relatively small number of countries in the world, the resulting histograms are very erratic. The histograms average around 3 countries per bin, depending on the year, which means that many bins end up with no countries at all. At the other end of the extreme, one bin ends up with China, which puts the (population-based) histogram literally off the chart.

The authors solve this problem by using a three-bin moving average to smooth out the results across adjacent bins. Even so, the resulting histograms are quite coarse. They delineated the zones using a formula that segmented zones at the troughs, with troughs defined as the mid-points between the peaks of adjacent zones. Korzeniewicz and Martin (1994) follow a virtually identical methodology, but use data for a larger number of countries and estimate zonal boundaries on an annual basis.

The income-based methodology is a sound approach to delineating the zones of the world-economy, and is firmly rooted in theory, but it is possible to substantially improve upon these two existing income-based studies. Babones (2002) made some improvements in smoothing technique, introducing normal random noise into the histograms to allow finer grained bins, but his methods were very computationally intensive and not easily replicated.

Below, I develop an improved methodology for creating income-based benchmarks of position in the world-economy using easily replicated techniques, the most up-to-date data, and a very fine histogram bin size. 
AN UPDATED INCOME APPROACH FOR DELINEATING THE ZONES OF THE WORLD-ECONOMY INTRODUCING THE STRUCTURE OF THE WORLD-ECONOMY (SWE) ANALYTICAL TOOL

Vast improvements in computing power and graphing techniques have made feasible the construction of more sophisticated histograms than those available to Arrighi and Drangel and Korzeniewicz and Martin (collectively, ADKM). In general outline, the income-based investigation of world-system structure in this paper echoes the ADKM methodology. Several refinements, however, result in superior clarity and accuracy than was possible using ADKM's techniques. In addition, the analysis has been brought up to date with data now available through 2002.

An important improvement introduced here is the construction of a Structure of the World-Economy (SWE) analytical tool. This is a Microsoft Excel spreadsheet that incorporates data on national income extracted from the World Bank's (2004) World Development Indicators database. These data are used to plot a smoothed histogram of the countries of the world (weighted by population) by logged national income level. The SWE tool is designed to be flexible and user-friendly: users with no programming knowledge can use dropdown menus to select from among six data series and four pre-defined panels of countries to customize their own model of the structure of the world-economy. Advanced spreadsheet users can tinker with the mechanics of the tool to easily produce even more variations with only minor changes to programming.

In what follows, I discuss the SWE implementation of the income approach in detail, highlighting similarities to and differences from the ADKM methodology. For a screenshot of the SWE interface, see Figure I. Reference to Figure I may be useful in understanding the details presented below.

\section{National Income Data}

Both ADKM studies operationalized national income as gross national product (GNP) per capita, expressed in dollars at current (contemporaneous) exchange rates, then deflated to constant 1970 dollars using a U.S. dollar price index. The resulting "real" national income figures (expressed in constant U.S. dollars) can then be used for inter-temporal comparisons of incomes as well as international comparisons. I refer to this as the FX methodology. The major drawback with the FX methodology is that reported exchange rates before the early I990s are largely official (rather than market) rates, which are often highly distorted.

In the SWE tool, I have implemented the GNP/FX operationalization of national income as one of six available operationalizations. The base year has
Figure 1 - Structure of the World-Economy Analytical Tool

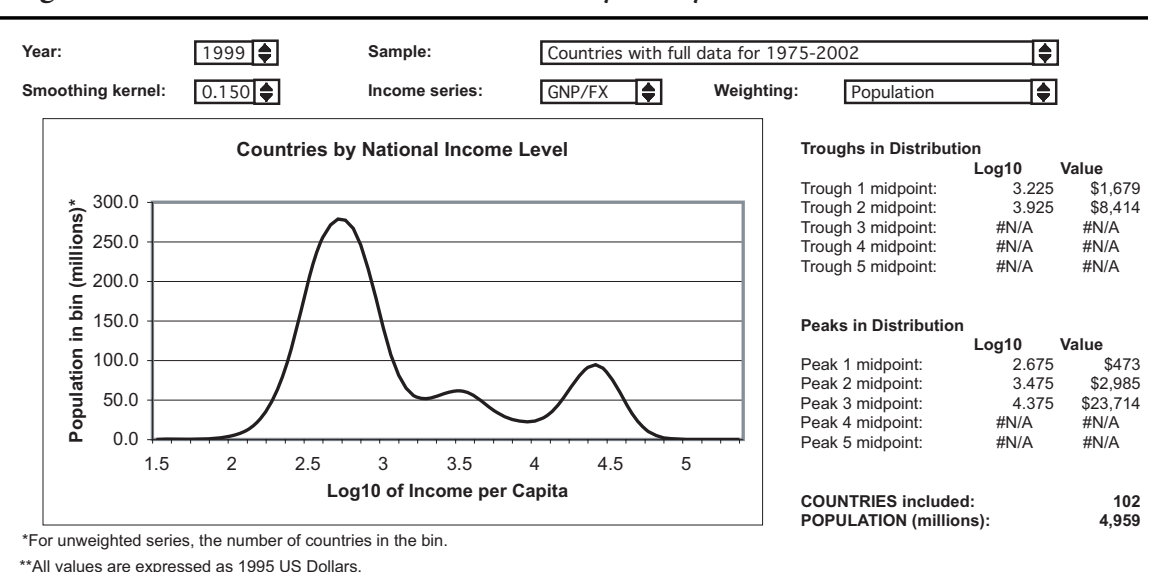

"*All values are expressed as 1995 US Dollars.

Technical Editor's Note: Above is a screenshot of the SWE analytical tool. The SWE analytical tool was created in Microsoft Excel and should be compatible with Microsoft Office ' 97 or above. The workbook is currently incompatible with OpenOffice, Gnumeric, KSpread, and Quattro Pro. File size is approximately $90 \mathrm{MB}$ uncompressed and is available for download in a number of compressed formats (see below). Readers who have older computers should be advised that the SWE analytical tool will run very slowly.

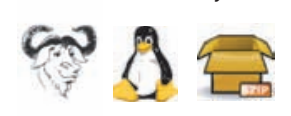

BZIP2 Archive File Size: $4.6 \mathrm{MB}$

Free Decompression Utilities: Windows: 7-Zip Mac oS X: Built-In bzip2 is a freely available, patent free, high-quality data compressor typically found on GNU/Linux systems.

http://jwsr.ucr.edu/jwsr-v11n1-swe.xls.bz2
Free Decompression Utilities Windows: 7-Zip Mac OS X: Stuffit Expander compression ratio typically found on Stuffit is a proprietary data compressor Windows systems. 7-Zip is free software typically found on Mac OS Classic and Mac distributed under the GNU LGPL. OS X systems.

http://jwsr.ucr.edu/jwsr-v11n1-swe.sit

\section{if 3 \\ Mac OS Stuffit Archive File Size: $3.6 \mathrm{MB}$}

http://jwsr.ucr.edu/jwsr-v11n1-swe.exe been updated to 1995 , but otherwise the methodology is identical. However, in addition to FX-based GNP, I make purchasing power parity (PPP) based figures available. PPP figures represent national income in welfare terms, adjusted for local (domestic) prices. They represent the quantity of goods and services that a country's GNP would enable it to buy on domestic markets within its own borders, rather than how much could be bought at world (international) prices.

I have also implemented a third operationalization of national income, which I call the "real local currency" (RLC) method. The RLC method sidesteps the controversy over exchange rate stability, instead converting all GNP figures to equivalent figures still in local currency terms but for a common base year for all countries. The base year I have implemented is 1995. Then, GNP figures are converted from local currency units to US Dollars using the exchange rate for that 
base year. The exchange rate chosen can be either FX or PPP based, although in the SWE only FX-based exchange rates have been implemented. The RLC method trades exchange rate error for inflation measurement error in local currency units; for many or most countries of the world, this might be preferable. The choice of base year for making currency conversions is arbitrary; 1995 was chosen as representing a period of relative stability and widely available market exchange rates.

World Bank "Atlas" method exchange rates have been used for both the FX and RLC operationalizations.

While the existing ADKM literature on world-system structure uses GNP (gross national product) as the measure of national income, the SWE also implements GDP (gross domestic product) income figures. In broad terms, GDP represents the sum total of goods and services produced within the borders of a country. GNP is equal to GDP plus net international transfers, such as repatriation of profits and individual remittances. Following the ADKM precedent, the results reported in this paper use the GNP/FX operationalization for national income, though all six possible combinations are available in the SWE tool.

The raw data for each of the six methods are drawn from the following World Bank (2004) data series:

GNP/PPP NY.GNP.MKTP.pp.CD—GNI, PPP (current international \$)

GDP/PPP NY.GDP.MKTP.Pp.CD—GDP, PPP (current international \$)

GNP/FX NY.GNP.ATLS.CD—GNI, Atlas method (current US\$)

GDP/FX NY.GDP.MKTP.CD—GDP (current US\$)

GNP/RLC NY.GNP.MKTP.CN—GNI (current LCU)

GDP/RLC NY.GDP.MKTP.CN_GDP (current LCU)

The other two data inputs are population and the domestic inflation rate for each country. The US GDP deflator is used to adjust all US Dollar figures to the 1995 base year:

Population SP.POP.TOTL-Population, total

Inflation NY.GDP.DEFL.ZS-GDP deflator (base year varies by country)

\section{Aggregating to a Smooth Histogram}

The AKDM studies construct histograms based on a bin width of .I on the $\log$ scale of GNP/FX per capita. The SWE implements a finer bin size of .05. Without smoothing, this bin size would yield a spiky, difficult to interpret histogram of the distribution of national incomes (see Figure 2).

The solution implemented by ADKM for the kind of spikes evident in Figure 2 is to introduce a multi-period moving average. While this yields an improvement in interpretability over the raw data, it still results in a relatively
Figure 2 - Countries by National Income Level (2002), Raw Data

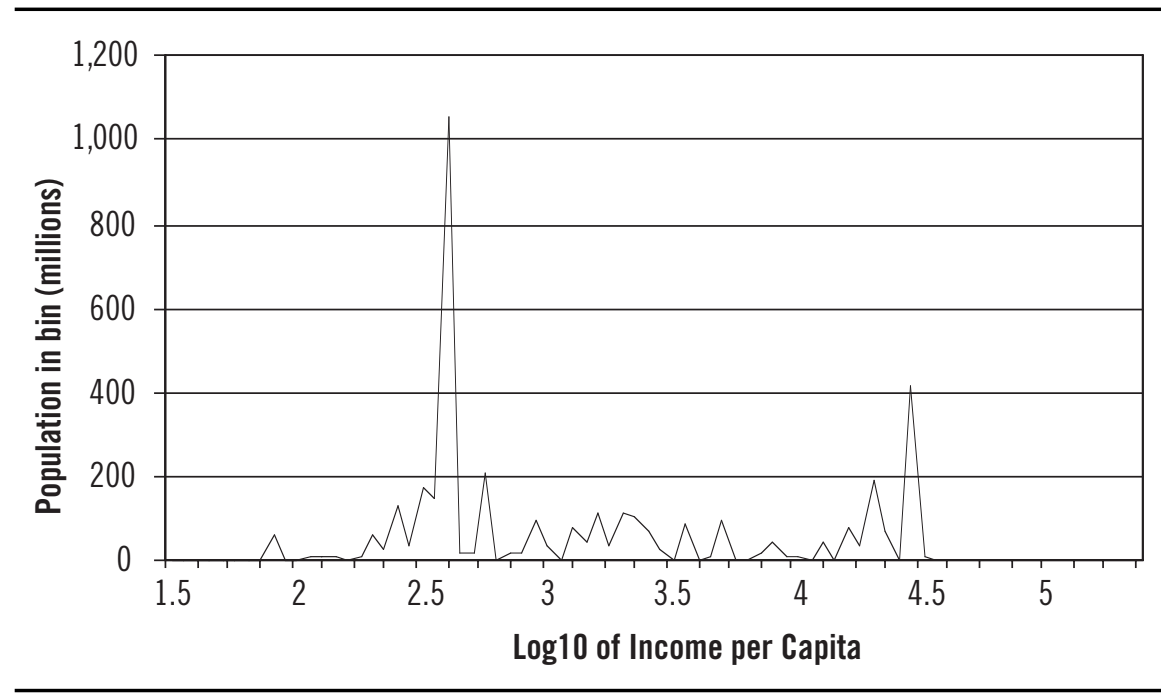

choppy histogram, since individual countries still "fall off" the moving average in discrete chunks. A better solution is to smooth the raw data with a function that has greater "memory" than the moving average function-one in which each country's influence on neighboring bins falls off gradually rather than suddenly. The gaussian kernel is one such function.

Gaussian kernel smoothing spreads each individual country's observation over a normal distribution of area on the histogram. The mean of this normal distribution is the observed national income level for the country, while its standard deviation can be defined by the user. As with any normal distribution, roughly $95 \%$ of a country's demographic weight will be apportioned within $+/-2$ standard deviations of the mean. For example, Brazil's national income level in 2002 was approximately 3.3 on the logio scale. Using a smoothing kernel with standard deviation I.5, its demographic weight, instead of being concentrated in a single bin, is spread out over roughly twelve bins, from 3.0 to 3.6 on the logio scale. The greatest weight, however, is still placed in the bins closest to the mean (Brazil's actual national income level). For an illustration, see Figure 3.

The SWE tool allows a choice of kernel standard deviations from o (no smoothing) to .2 (extreme smoothing), in increments of .OI. (Note that for technical computational reasons, "o" is actually implemented as a standard deviation of .ooI, a difference that cannot be detected in the resulting histograms.) There is no theoretical guidance as to what is an "appropriate" level of smoothing. Values in the vicinity of I.O seem to eliminate individual country spikes without obscur- 
Figure 3 - Illustration of Smoothing Kernel (Brazil 2002, SD=.150)

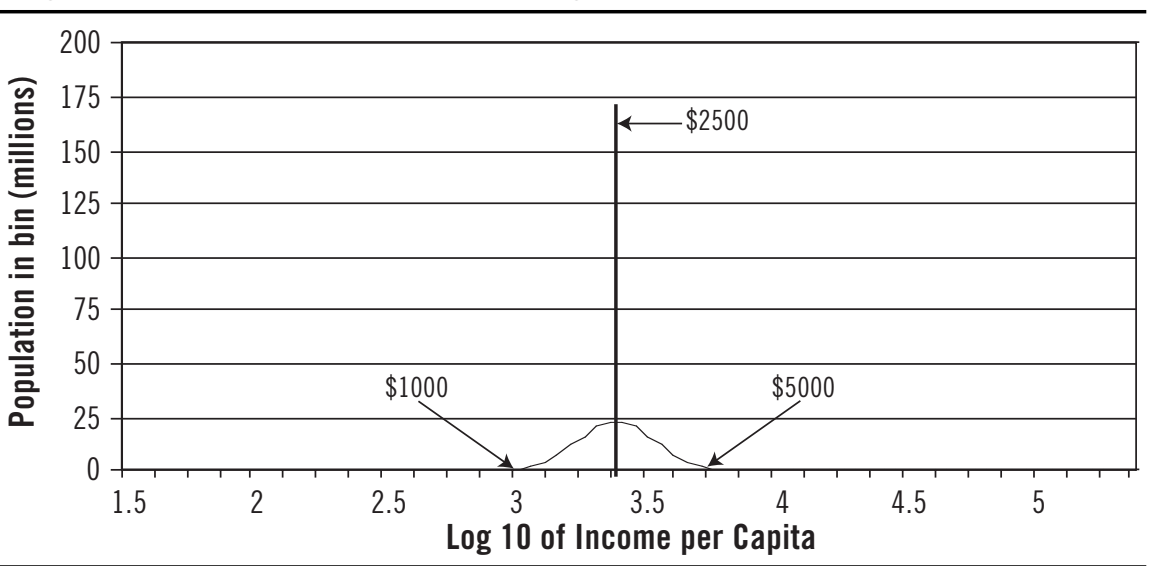

ing the overall shape of the histogram. Smoothing levels much greater than .2 blur out all detail in the resulting histograms. The results reported below use a kernel of 1.5 . A kernel of standard deviation I.O was used initially, producing very similar results, but transitions of countries across zonal boundaries sometimes caused annual instability in the specific locations of those boundaries. Increasing the smoothing kernel standard deviation to 1.5 eliminated this problem while leaving the general structure of the histograms unchanged.

\section{Country Panels}

Four pre-set panels of countries are programmed into the SWE tool: countries with full data (all income series) for 1975-2002 (allows uniform comparison across all years and income operationalizations); countries with data for 1975-2002 for the chosen income series (allows uniform comparison across all years for any given income operationalization); countries with data in the chosen year for all six income series (allows uniform comparison within one year across all income operationalizations); countries with data in the chosen year for the chosen income series (maximizes the number of countries available for one particular choice of year and income operationalization). The period 1975-2002 has been chosen as a benchmark period for two reasons. First, by 1975 substantially all of the countries of the world had achieved independence. Second, the World Bank's PPP series begin in 1975. Advanced users can easily use the general infrastructure of the SWE tool to build their own custom panels.

\section{Population Weighting}

The SWE tool offers four options for weighting countries: population weighting; population weighting with China excluded; no weighting; no weighting with all countries with 1995 populations under Io million excluded. It is anticipated that most analysts will use the full population weights, as do the results presented in this paper. An option has been hard-coded, however, to allow users to exclude China. (Advanced users can easily modify the tool to exclude any countries they choose by modifying the "NOLARGE" field on the Series Lookup page.) China and India each represent a substantial proportion of total world population, and thus any movement by China or India across zones of the world-economy would obliterate the resolution of the boundary between zones. In this regard, India is non-problematic, since its position in the world economy has changed little over the past forty years, and its recent rapid development has yet to lift it out of peripheral status. The treatment of China is more problematic. While it is still on the whole a poor country, its large demographic weight, combined with the kernel smoothing used in the SWE tool, can lead to a blurring of zonal boundaries. As a result, the SWE tool contains an option for excluding China from all calculations. In the results reported below, China has, in fact, been excluded, on the argument that China's recent growth, while remarkable, has not altered the rationale for categorizing the remaining countries of the world into peripheral, semiperipheral, and core zones.

\section{Peak and Trough Analyses}

Routines for automatically identifying peaks and troughs in the world-economy histograms have been incorporated into the SWE tool. A maximum of five peaks and five troughs (beginning from the left of the histogram) will be identified. Advanced users can easily customize this to as many peaks and troughs as are desired.

A peak (trough) is defined as a relative maximum (minimum) point over a range of seven histogram bins. Peaks are only reported if they represent a population weight equal to at least $\mathrm{I} \%$ of the world total in a single bin. Troughs are only reported if they represent a population weight of not more than $2 \%$ of the world total in a single bin. These two conditions prevent the reporting of "false" peaks and troughs that can arise from twin-peaked modes.

In addition to peaks and troughs, the total number of countries represented in the histogram and their combined population are reported on the cover sheet of the SWE tool. 
Figure 4 - Countries by National Income Level (1975)

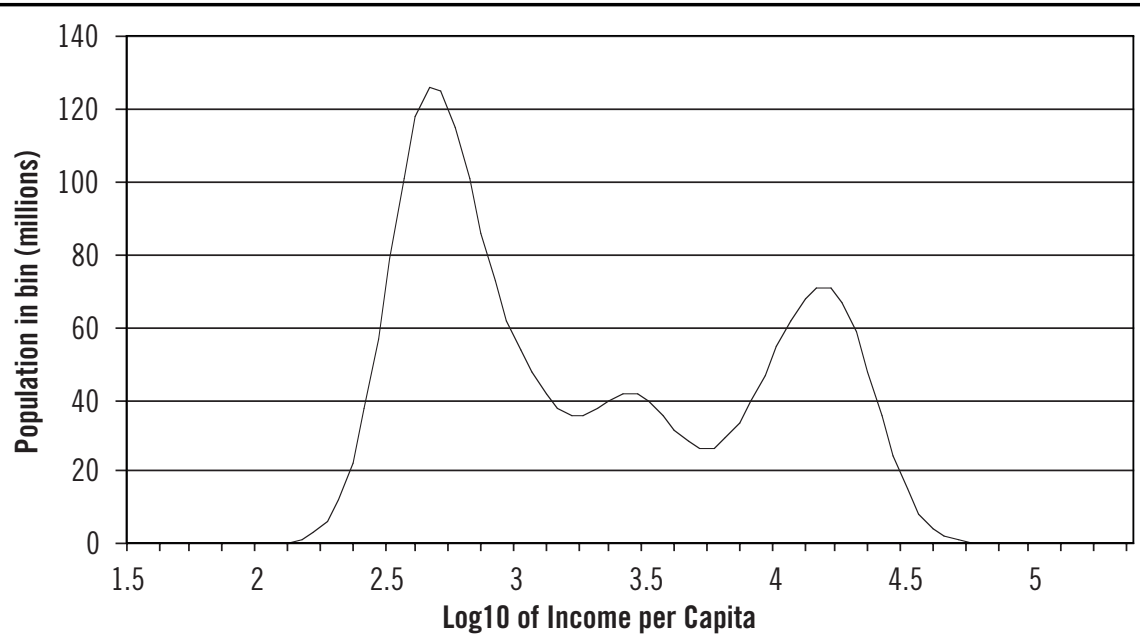

Figure 5 - Countries by National Income Level (1980)

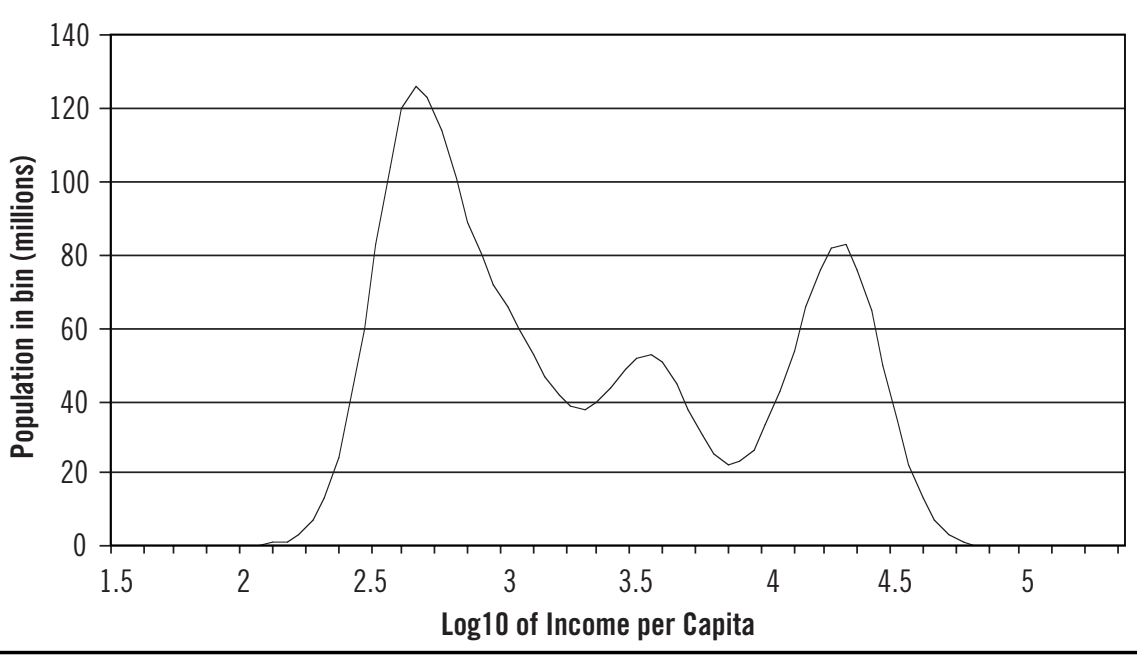

\section{RESULTS}

As an initial trial, the SWE tool has been used to chart the structure of the world-economy for the years 1975-2002, using a continuous panel of IO3 countries with data available for the GNP/FX operationalization. A kernel standard deviation of $\mathrm{I} .5$ has been chosen, and China has been excluded. Snapshots of this distribution at five-year intervals (1975, 1980, 1985, 1990, 1995, 2000) are reported in Figures 4-9.
Figure 6 - Countries by National Income Level (1985)

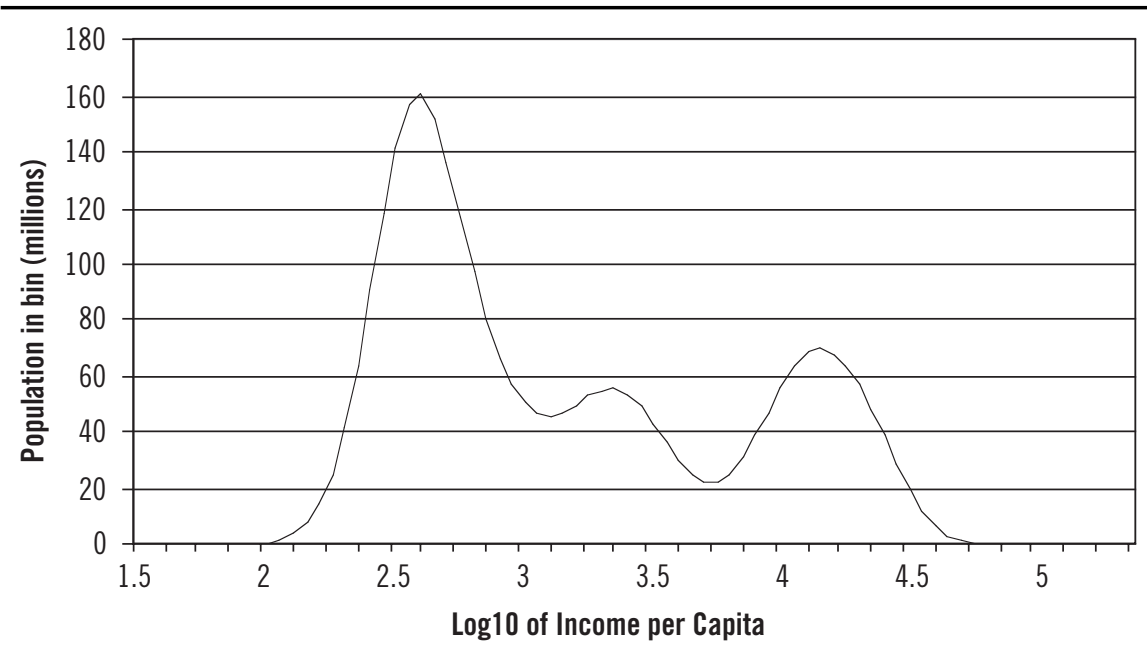

Figure 7 - Countries by National Income Level (1990)

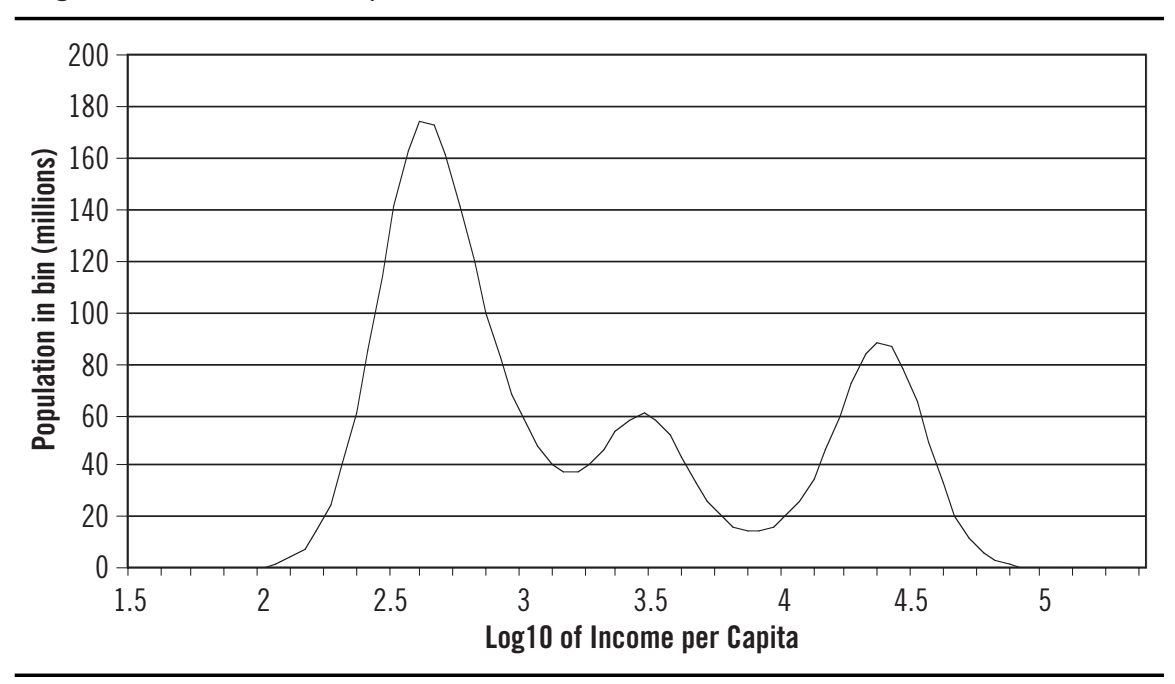

\section{Perimeter of the Periphery, Perimeter of the Core, and Zonal Modes}

The existence of a tri-modal distribution of countries (weighted by population) in the distribution of national incomes is unmistakable. Through all twenty-eight study years (1975-2002), a smooth and continuous metamorphosis of one year's histogram into another's is maintained. Clear troughs in the histograms for every year mark the perimeter of the core (PC) and perimeter of the periphery (PP) (Arrighi and Drangel 1986). Peaks and troughs in the structure 
Figure 8 - Countries by National Income Level (1995)

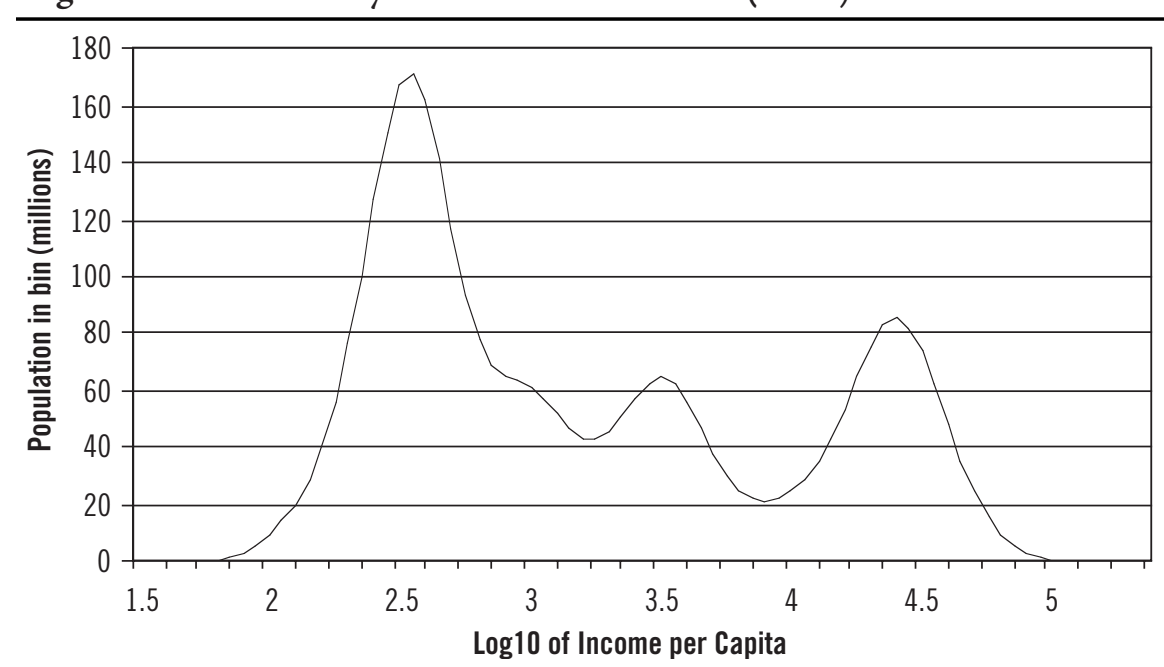

Figure 9 - Countries by National Income Level (2000)

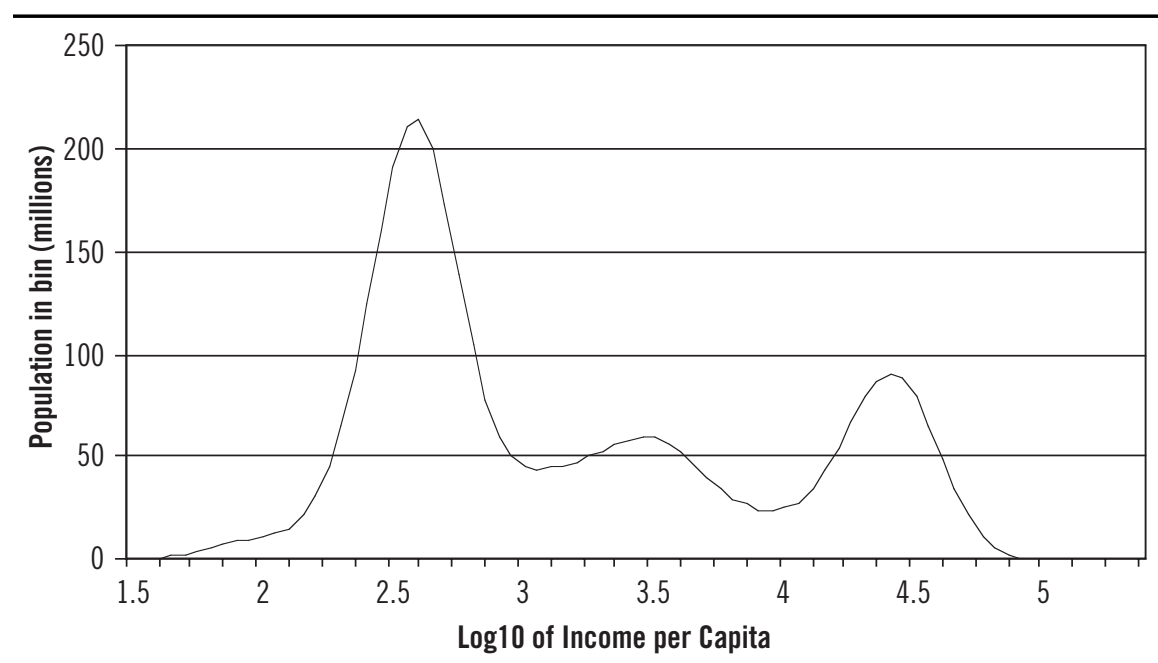

of national income in the world-economy for $1975-2002$ are reported in Table I (in 1995 US Dollars) and graphed in Figure io (on a logio scale).

Figure Io charts the trajectory over time of the distributional peaks, or modes, of the core (MC), semiperiphery (MP) and periphery (MP). It also graphs the evolution of the core-semiperiphery boundary (the "perimeter of the core" or $\mathrm{PC}$ ) and the semiperiphery-periphery boundary (the "perimeter of the periphery" or PP). A careful examination of Figure Io reveals two salient features. First,
Table 1 - Defining Points of the World-Economy, 1975-2002

\begin{tabular}{|c|c|c|c|c|c|}
\hline Year & MC & PC & MS & PP & MP \\
\hline 1975 & $\$ 13,335$ & $\$ 4,732$ & $\$ 2,661$ & $\$ 1,679$ & $\$ 422$ \\
\hline 1976 & $\$ 14,962$ & $\$ 5,309$ & $\$ 2,661$ & $\$ 1,679$ & $\$ 376$ \\
\hline 1977 & $\$ 14,962$ & $\$ 5,309$ & $\$ 2,661$ & $\$ 1,496$ & $\$ 376$ \\
\hline 1978 & $\$ 14,962$ & $\$ 5,309$ & $\$ 2,661$ & $\$ 1,679$ & $\$ 376$ \\
\hline 1979 & $\$ 16,788$ & $\$ 6,683$ & $\$ 2,985$ & $\$ 1,679$ & $\$ 376$ \\
\hline 1980 & $\$ 18,836$ & $\$ 6,683$ & $\$ 3,350$ & $\$ 1,884$ & $\$ 422$ \\
\hline 1981 & $\$ 16,788$ & $\$ 6,683$ & $\$ 2,985$ & $\$ 1,679$ & $\$ 422$ \\
\hline 1982 & $\$ 14,962$ & $\$ 5,957$ & $\$ 2,661$ & $\$ 1,679$ & $\$ 376$ \\
\hline 1983 & $\$ 13,335$ & $\$ 5,309$ & $\$ 2,371$ & $\$ 1,334$ & $\$ 376$ \\
\hline 1984 & $\$ 13,335$ & $\$ 5,309$ & $\$ 2,113$ & $\$ 1,189$ & $\$ 376$ \\
\hline 1985 & $\$ 13,335$ & $\$ 4,732$ & $\$ 2,113$ & $\$ 1,189$ & $\$ 376$ \\
\hline 1986 & $\$ 14,962$ & $\$ 5,309$ & $\$ 2,113$ & $\$ 1,189$ & $\$ 376$ \\
\hline 1987 & $\$ 18,836$ & $\$ 5,957$ & $\$ 2,113$ & $\$ 1,334$ & $\$ 422$ \\
\hline 1988 & $\$ 21,135$ & $\$ 6,683$ & $\$ 2,371$ & $\$ 1,334$ & $\$ 422$ \\
\hline 1989 & $\$ 21,135$ & $\$ 6,683$ & $\$ 2,661$ & $\$ 1,496$ & $\$ 422$ \\
\hline 1990 & $\$ 21,135$ & $\$ 7,499$ & $\$ 2,661$ & $\$ 1,496$ & $\$ 376$ \\
\hline 1991 & $\$ 21,135$ & $\$ 7,499$ & $\$ 2,661$ & $\$ 1,334$ & $\$ 335$ \\
\hline 1992 & $\$ 23,714$ & $\$ 7,499$ & $\$ 2,661$ & $\$ 1,496$ & $\$ 335$ \\
\hline 1993 & $\$ 23,714$ & $\$ 7,499$ & $\$ 2,661$ & $\$ 1,496$ & $\$ 299$ \\
\hline 1994 & $\$ 23,714$ & $\$ 7,499$ & $\$ 2,661$ & $\$ 1,496$ & $\$ 299$ \\
\hline 1995 & $\$ 23,714$ & $\$ 7,499$ & $\$ 2,985$ & $\$ 1,679$ & $\$ 335$ \\
\hline 1996 & $\$ 23,714$ & $\$ 7,499$ & $\$ 2,985$ & $\$ 1,679$ & $\$ 335$ \\
\hline 1997 & $\$ 23,714$ & $\$ 8,414$ & $\$ 3,350$ & $\$ 1,679$ & $\$ 335$ \\
\hline 1998 & $\$ 23,714$ & $\$ 8,414$ & $\$ 3,350$ & $\$ 1,334$ & $\$ 376$ \\
\hline 1999 & $\$ 23,714$ & $\$ 8,414$ & $\$ 2,985$ & $\$ 1,189$ & $\$ 376$ \\
\hline 2000 & $\$ 23,714$ & $\$ 8,414$ & $\$ 2,661$ & $\$ 1,059$ & $\$ 376$ \\
\hline 2001 & $\$ 23,714$ & $\$ 8,414$ & $\$ 1,884$ & $\$ 1,059$ & $\$ 376$ \\
\hline 2002 & $\$ 23,714$ & $\$ 7,499$ & $\$ 1,884$ & $\$ 1,059$ & $\$ 376$ \\
\hline \multicolumn{3}{|c|}{ PC Perimeter of the Core } & MS & \multicolumn{2}{|c|}{ Median of the Semiperiphery } \\
\hline \multicolumn{3}{|c|}{ PP Perimeter of the Periphery } & MP & \multicolumn{2}{|c|}{ Median of the Periphery } \\
\hline \multicolumn{3}{|c|}{ MC Median of the Core } & & & \\
\hline
\end{tabular}

of the three zones, only the core has experienced consistent growth, with both its mode and its upper boundary generally increasing over time. Second, the range of national incomes in the semiperiphery has widened substantially over time. Tracing the trajectories of the modes of the semiperiphery and periphery under- 
Figure 10 - Modes and Perimeter Point of the Zones of the World-Economy, 1975-2002

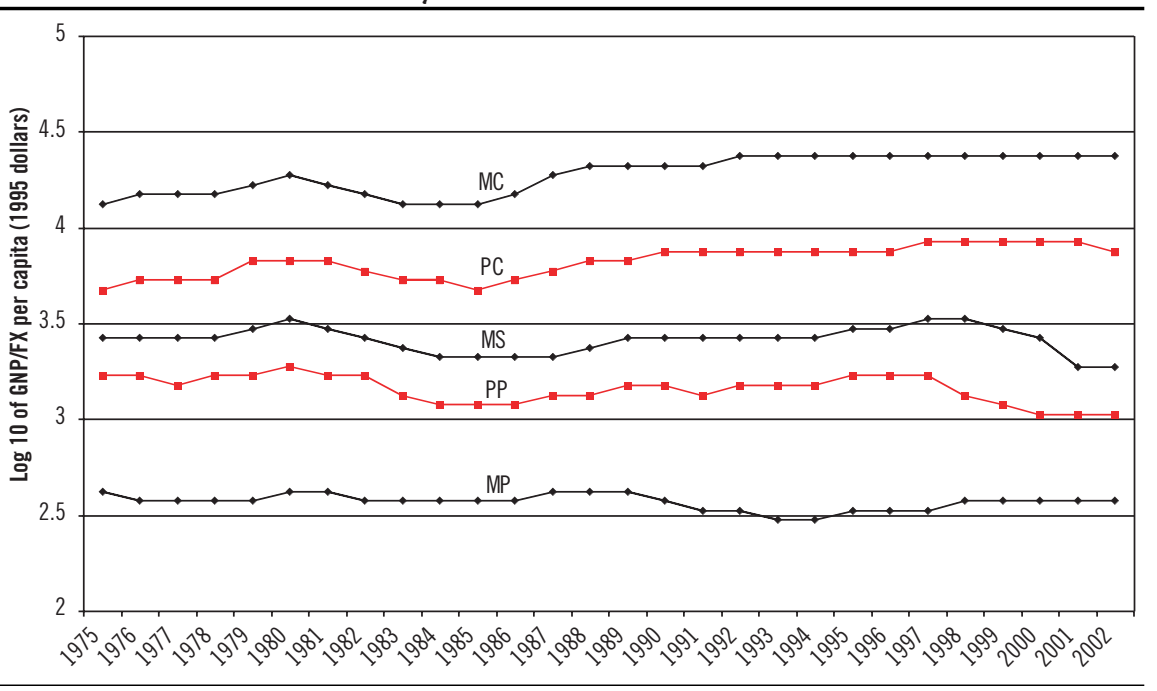

scores just how little growth these zones have experienced over the past twentyeight years.

\section{Mobility and the "Organic" Periphery, Semiperiphery, and Core}

Given this long-run stability of the structure of the world-economy, it is meaningful to speak of sets of countries that are "organically" core, semiperipheral, or peripheral countries. These are countries that, in terms of income, typify each of the three zones (respectively). I have compiled a list of the countries that have been consistently classified into a single one of the three zones of the worldeconomy over the entire 28-year study period. Seventy-three out of IO3 countries in the study fit this definition of "organic" zone membership. In contrast to some other lists of organic zone membership, no special exclusions have been made based country size, oil exporting status, and the like. The countries are reported by zone in Table 2 .

Clearly, the striking feature of Table 2 is the shortage of "organically" semiperipheral countries. This is, however, not so surprising. Since the semiperiphery is an intermediate category, it is possible for countries to move through it in both directions, whereas both the core and the periphery have "hard" boundaries on one side. Countries never rise above the core, nor do they fall below the periphery. In any case, the three big classically semiperipheral countries-Mexico, Brazil, and South Africa-do fall into the organic semiperiphery as operationalized here.
Table 2 - Countries that Are "Organic" to Each Zone of the

World Economy

\begin{tabular}{llll}
\hline Core & Semiperiphery & \multicolumn{2}{c}{ Periphery } \\
\hline Australia & Belize & Bangladesh & Papua New Guinea \\
Austria & Brazil & Benin & Philippines \\
Belgium & Chile & Bolivia & Rwanda \\
Canada & Fiji & Burkina Faso & Senegal \\
Denmark & Hungary & Burundi & Sierra Leone \\
Finland & Jamaica & Central African Republic & Solomon Islands \\
France & Malaysia & Chad & Sri Lanka \\
Germany & Mexico & China & Sudan \\
Greece & Panama & Congo, Dem. Rep. & Togo \\
Hong Kong, China & Seychelles & Gambia, The & Zambia \\
Iceland & South Africa & Ghana & \\
Ireland & Tunisia & Guinea-Bissau & \\
Israel & Turkey & Haiti & \\
Italy & Uruguay & Honduras & \\
Japan & & India & \\
Luxembourg & & Indonesia & \\
Netherlands & & Kenya & \\
New Zealand & & Lesotho & \\
Norway & & Madagascar & \\
Singapore & & Malawi & \\
Spain & & Mauritania & \\
Sweden & & Nepal & \\
Switzerland & & Niger & \\
United Kingdom & & Pakistan & \\
United States & & & \\
\hline
\end{tabular}

Thirty of the IO3 countries in the panel did experience moves across zonal boundaries over the period 1975-2002. While this may seem like a substantial amount of mobility, most of this represents demographically small countries that have historically hovered near the zonal boundaries. These 30 countries accounted for 75 total moves across zonal boundaries: 4I cases of upward mobility and 34 cases of downward mobility. Only I7 countries made stable one-way transitions of boundaries over the 28 year study period, out of a total of IO3 countries in the panel ("permanence" being defined as a zonal shift lasting five years or more). With the dramatic exception of South Korea, most of these transitions were related to changes in the prices of natural resources (see Table 3). Overall, the structure of the world-economy has been very stable over time, with little mobility across boundaries of its three zones. 
Table 3 - Eighteen Examples of Permanent Mobility (Transition Lasting a Minimum of Five Years)

\begin{tabular}{lllll}
\hline Country & Direction & Year & From & To \\
\hline Algeria & Up & 1998 & Periphery & Semiperiphery \\
Botswana & Up & 1980 & Periphery & Semiperiphery \\
Cameroon & Down & 1989 & Semiperiphery & Periphery \\
Costa Rica & Up & 1983 & Periphery & Semiperiphery \\
El Salvador & Up & 1997 & Periphery & Semiperiphery \\
Gabon & Down & 1986 & Core & Semiperiphery \\
Guyana & Down & 1976 & Semiperiphery & Periphery \\
Malta & Up & 1988 & Semiperiphery & Core \\
Nicaragua & Down & 1978 & Semiperiphery & Periphery \\
Saudi Arabia & Down & 1997 & Core & Semiperiphery \\
St. Vincent and the Grenadines & Up & 1984 & Periphery & Semiperiphery \\
South Korea & Up & 1976 & Periphery & Semiperiphery \\
South Korea & Up & 1992 & Semiperiphery & Core \\
Swaziland & Down & 1989 & Semiperiphery & Periphery \\
Syrian Arab Republic & Down & 1989 & Semiperiphery & Periphery \\
Thailand & Up & 1988 & Periphery & Semiperiphery \\
Trinidad and Tobago & Down & 1987 & Core & Semiperiphery \\
Venezuela, RB & Down & 1986 & Core & Semiperiphery \\
\hline
\end{tabular}

\section{CONCLUSION}

The SWE tool represents a comprehensive treatment of the use of national income statistics to illustrate the structure of the modern world-economy. It incorporates the methods used in previous income-based approached to worldsystem structure, but allows much greater flexibility. As the SWE is updated, future versions will likely incorporate additional pre-defined panels as well as taking advantage of the most recent data. In addition, as desktop computing power increases each year, finer and finer grained analyses will become possible. Due to its ease of use and updating, the SWE makes it realistic to track shifts in the boundaries separating zones of the world-economy on an annual basis, extrapolating the continuous time series already available for 1960-2002. Equally important, users can customize the SWE to chart the structure of the worldeconomy based on their own preferred input assumptions. Thus, those who disagree with the methodological choices made in this paper can easily experiment with the parameters of the SWE tool to arrive at their own conclusions.

Substantively, the empirical results presented here confirm the long-held view that the world-economy is divided into three clear zones by national income level and that this division has been stable over a substantial period of time. The overall impression given by Figure Io and Table 3 is that the semiperiphery is slowly but surely expanding at the expense of the other two zones. The range of national incomes represented in the semiperiphery roughly doubled over the study period, and eleven of eighteen observed "permanent" transitions were into the semiperiphery from other zones. Arrighi and Drangel are probably right to model the semiperiphery not as a transitional stage on the road to development, but as a permanent position in the world-economy. On the other hand, several examples suggest that contra Arrighi and Drangel upward mobility from the periphery to the semiperiphery is achievable - and for many countries, such a transition would represent a major improvement in living standards.

This suggests that perhaps we should consider shifting our mindset in thinking about development. Since much of the academic study of development is conducted by core-based scholars, there exists a bias towards defining development in terms of growth towards core country status. Terminology reflects this bias: the label "less-developed country" (LDC) is applied equally to semiperipheral and peripheral economies, whereas the "developed" countries are, broadly speaking, the countries of the core of the world-economy. Rather than taking core county policies (free trade, liberalized capital accounts, floating currencies, etc.) as models to apply in all LDCs, it might make more sense to use semiperipheral countries as aspirational models for peripheral economies. In other words, the world might get more bang for its development buck by fostering transitions from the periphery to the semiperiphery, rather than shooting for the seemingly out-of-reach goal of seeking transitions to the core.

Transitions from the semiperiphery to the core have historically been rare, and have largely driven by chance (e+g, the discovery of oil) or massive transfers (e.g., membership in the EU). Neither mechanism can be relied upon to drive policy in the poorer countries of the world more broadly. Of the independent transitions to core status, Malta cannot be taken as a model, since its rise is almost entirely due to its strategic position astride Mediterranean shipping lanes. This leaves the case of South Korea as the sole example of a poor country rising to core status after 1975 - though even in the Korean case some have suggested that there has been an element of "development by invitation" (Cumings I984). Keeping in mind that the vast majority of the world's population lives in the periphery of the world-economy, it would not be an unworthy goal to focus on ways to help peripheral countries attain semiperipheral income levels. While the current research gives no guidance on how to accomplish this goal, it does suggest that such a goal might be productively pursued. 


\section{REFERENCES}

Arrighi, Giovanni, and Jessica Drangel. I986. "The Stratification of the WorldEconomy: An Exploration of the Semiperipheral Zone." Review I0: 9-74.

Babones, Salvatore J. 2002. The International Structure of Income and Its Implications for Economic Growth, 1960-2000. Ph.D. dissertation, Department of Sociology, The Johns Hopkins University, Baltimore, MD.

Chase-Dunn, Christopher. 1998. Global Formation: Structures of the World-Economy. Oxford: Basil Blackwell.

Chase-Dunn, Christopher, and Thomas D. Hall. 1997. Rise and Demise: Comparing World-Systems. Boulder, CO: Westview Press.

Cumings, Bruce. 1984. "The Origins and Development of the Northeast Asian Political Economy: Industrial Sectors, Product Cycles, and Political Consequences." International Organization 38:I-40.

Kentor, Jeffrey. 2000. Capital and Coercion: The Economic and Military Processes that Have Shaped the World Economy 1800-1990. New York: Garland Publishing.

Kick, Edward L. 1987. "World-System Structure, Nationalist Development, and the Prospects for a Socialist World Order." Pp. I27-I55 in America's Changing Role in the World-System, edited by Terry Boswell and Albert Bergesen. New York: Praeger.

Korzeniewicz, Roberto Patricio, and William Martin. 1994. “The Global Distribution of Commodity Chains." PP. 67-9I in Commodity Chains and Global Capitalism, edited by Gary Gereffi and Miguel Korzeniewicz. Westport, CT: Praeger.

Nemeth, Roger, and David A. Smith. 1985. "International Trade and World-System Structure: A Multiple Network Analysis." Review 8: 5I7-560.

Smith, David A. and Douglas R. White. I99I. "Structure and Dynamics of the Global Economy" Network Analysis of International Trade 1965-80." Social Forces 70: 857-893.

Snyder, David, and Edward Kick. 1979. "Structural Position in the WorldSystem and Economic Growth, 1955-1970: A Multiple-Network Analysis of Transnational Interactions." American Journal of Sociology 84: 1096-II 26.

Terlouw, Cornelius P. 1992. The Regional Geography of the World System: External Area, Periphery, Semi-periphery, Core. Utrecht: Faculteit Ruimtelijke Wetenschappen.

Terlouw, Cornelius P. 1993. “The Elusive Semiperiphery: A Critical Examination of the Concept Semiperiphery." International Journal of Comparative Sociology 34: 87-I02.

Van Rossem, Ronan. 1996. "The World-System Paradigm as General Theory of Development: A Cross-National Test." American Sociological Review 61: 508-527.

Wallerstein, Immanuel M. I974. The Modern World-System I: Capitalist Agriculture and the Origins of the European World-Economy in the Sixteenth Century. New York: Academic Press.
Wallerstein, Immanuel M. 1979. The Capitalist World-Economy. Cambridge: Cambridge University Press.

World Bank. 2004. World Development Indicators. Washington, D.C.: World Bank. 